\title{
Solvation and Speciation of Cobalt(II). A Theoretical X-Ray Absorption and RIXS Study
}

Basmah H. Allehyani ${ }^{\mathrm{a}}$, Walid I. Hassan ${ }^{\mathrm{a}, \mathrm{b}}$, Saadullah G. Aziz ${ }^{\mathrm{a}}$, Rifaat H. Hilal ${ }^{\mathrm{b}}$, Oliver Kühn , Sergey I. Bokarev ${ }^{\mathrm{c}, *}$

a Chemistry Department, Faculty of Science, King Abdulaziz University, 21589 Jeddah, Saudi-Arabia

${ }^{\mathrm{b}}$ Chemistry Department, Faculty of Science, Cairo University, Giza, Egypt

c Institute of Physics, University of Rostock, Albert-Einstein-Str. 23-24, D-18059 Rostock, Germany

\begin{abstract}
The X-ray spectroscopic signatures of solvated $\mathrm{Co}^{2+}$ ions mimicking the aqueous solution of $\mathrm{CoCl}_{2}$ are investigated accounting for multiconfigurational as well as spin-orbit coupling effects. To this end the RASSCF/RASSI methodology with second order corrections due to dynamical correlation (RASPT2) is employed. Emphasis is put on the identification of spectral signatures of different species in octahedral, $\left[\mathrm{Co}\left(\mathrm{H}_{2} \mathrm{O}\right)_{6-\mathrm{x}} \mathrm{Cl}_{\mathrm{x}}\right]^{(2-\mathrm{x})^{+}}$, and tetrahedral, $\left[\mathrm{Co}\left(\mathrm{H}_{2} \mathrm{O}\right)_{4-\mathrm{x}} \mathrm{Cl}_{\mathrm{x}}\right]^{(2-\mathrm{x})+}$, coordination. X-ray absorption spectra show distinct differences in the $\mathrm{L}_{3}$ band only. Here, the best agreement between theory and experiment is obtained for the hexaaqua complex $\left[\mathrm{Co}\left(\mathrm{H}_{2} \mathrm{O}\right)_{6}\right]^{2+}$. For better identification of particular species it is proposed to use RIXS spectroscopy, which shows pronounced species-dependent inelastic features.
\end{abstract}

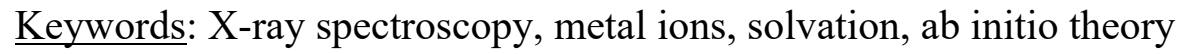

\footnotetext{
${ }^{*}$ Corresponding author, Email: sergey.bokarev@uni-rostock.de (S.I. Bokarev)
} 


\section{Introduction}

$\mathrm{X}$-ray spectroscopy provides a tool for an element-specific investigation of the electronic structure of matter $[1,2]$. In particular applications to metal ligand interactions continue to attract considerable attention due to their importance for a number of processes in coordination chemistry [3-5], (photo)catalysis [6,7], and biochemistry [8]. Much effort has been devoted to solvated transition metal ions. They are not only interesting in their own, but they also provide model systems for studying the influence of the surrounding on the metal's electronic structure. Examples for joint experimental and theoretical X-ray absorption (XAS) and/or Resonant Inelastic Scattering (RIXS) studies include, for instance, aqueous $\mathrm{Fe}^{2+}, \mathrm{Fe}^{3+}$, and $\mathrm{Co}^{2+}$ [9-11], $\mathrm{Ni}^{2+}$ [12] as well as $\mathrm{Cr}^{3+}$ [13]. Here, the Restricted Active Space SelfConsistent Field (RASSCF) protocol including second order corrections for dynamic correlation (RASPT2) is applied to the study of the L-edge XAS and RIXS spectra of cobalt complexes, which serve as a model for the $\mathrm{CoCl}_{2}$ salt in aqueous solution [9]. $\mathrm{CoCl}_{2}$ undergoes electrolytic dissociation and $\mathrm{Co}^{2+}$ ions are solvated by water molecules. Ideally, this results in a hexaaqua $\left[\mathrm{Co}\left(\mathrm{H}_{2} \mathrm{O}\right)_{6}\right]^{2+}$ complex. However, the dissociation may not occur completely and its degree, in general, should depend on time elapsed since the solution has been prepared and the concentration of the salt. Thus, one can find ions of general formula $\left[\mathrm{Co}\left(\mathrm{H}_{2} \mathrm{O}\right)_{6-\mathrm{x}} \mathrm{Cl}_{\mathrm{x}}\right]^{(2-\mathrm{x})+}$ in solution. Besides these octahedrally coordinated complexes, especially at higher temperature the tetrahedral $\left[\mathrm{Co}\left(\mathrm{H}_{2} \mathrm{O}\right)_{4-\mathrm{x}} \mathrm{Cl}_{\mathrm{x}}\right]^{(2-\mathrm{x})+}$ complexes are likely to occur [14]. Thus, there is a considerable number of species that can form an equilibrium, which depends on the experimental conditions. The actual speciation of solvated $\mathrm{Co}^{2+}$ is not only of fundamental scientific interest, but has a number of practical implications, e.g. in cobalt transport and deposition in ore-forming hydrothermal systems [14] or due to the cytotoxic effects of cobalt on human cells [15]. This provides the motivation for extending our previous study on the XAS of $\left[\mathrm{Co}\left(\mathrm{H}_{2} \mathrm{O}\right)_{6}\right]^{2+}[9]$ towards the full set of species $\left[\mathrm{Co}\left(\mathrm{H}_{2} \mathrm{O}\right)_{6-\mathrm{x}} \mathrm{Cl}_{\mathrm{x}}\right]^{(2-\mathrm{x})^{+}}$and $\left[\mathrm{Co}\left(\mathrm{H}_{2} \mathrm{O}\right)_{4-\mathrm{x}} \mathrm{Cl}_{\mathrm{x}}\right]^{(2-\mathrm{x})+}$. Since the goal is the identification of their characteristic X-ray spectroscopic features, we will also report on RIXS spectra.

The availability of high-level electronic structure calculations is vital for the correct interpretation of experimental X-ray spectra. While K-edges are well described using timedependent density functional theory [16], the multiconfiguration and strong spin-orbit coupling (SOC) effects pertinent to transition metal L-edges make correlated wave function approaches the method of choice. Recently, a theoretical protocol based on the RASSCF method [17] has been successfully applied to studies of XAS $[9,18]$, RIXS $[5,6,12,19]$, partial fluorescence yield [10,13], photoelectron [20-22], and Auger [23] spectra, for a review see Ref. [2].

This article is organized as follows: In Section 2 we briefly describe the computational protocol for the calculation of XAS and RIXS spectra. Results will be presented in Section 3 for octahedral $\left[\mathrm{Co}\left(\mathrm{H}_{2} \mathrm{O}\right)_{6-\mathrm{x}} \mathrm{Cl}_{\mathrm{x}}\right]^{(2-\mathrm{x})^{+}}$and tetrahedral $\left[\mathrm{Co}\left(\mathrm{H}_{2} \mathrm{O}\right)_{4-\mathrm{x}} \mathrm{Cl}_{\mathrm{x}}\right]^{(2-\mathrm{x})^{+}}$complexes. A summary is provided in Section 4.

\section{Computational details}

The solvation of the $\mathrm{Co}^{2+}$ ion was modeled taking into account the first solvation shell only, i.e. complexes of octahedral $\left[\mathrm{Co}\left(\mathrm{H}_{2} \mathrm{O}\right)_{6-\mathrm{x}} \mathrm{Cl}_{\mathrm{x}}\right]^{(2-\mathrm{x}){ }^{+}}$and tetrahedral $\left[\mathrm{Co}\left(\mathrm{H}_{2} \mathrm{O}\right)_{4-\mathrm{x}} \mathrm{Cl}_{\mathrm{x}}\right]^{(2-\mathrm{x}){ }^{+}}$type have been considered. This approximation is justified by the locality of the X-ray probe. The equilibrium geometries of the complexes in their high-spin ground states have been obtain for the highest possible symmetry within octahedral and tetrahedral coordination at the Hartree- 
Fock HF/aug-cc-pTVZ level of theory using the Gaussian09 program [24]. Note that geometry optimization using density functional theory (B3LYP functional) yielded a lower symmetry coordination shell. Therefore, and also because highly accurate values for metal ligand bond distances are not required for the present purpose, we have used the Hartree-Fock geometries throughout. The high-spin nature of the ground state in each case has been proven by the RASSCF/RASPT2 calculations, see below.

The core- and valence-excited states were calculated using the RASSCF method [25], employing the ANO-RCC basis set for all atoms [26]. Three levels of basis set contraction were applied, i.e. double-zeta (ANO-RCC-VDZ), triple-zeta (ANO-RCC-VTZ), and quadrupole zeta (ANO-RCC-VQZ). The active space included three $\mathrm{Co}^{2+} 2 \mathrm{p}$ (one hole is allowed, RAS1) and five 3d orbitals: $3 \mathrm{~d}\left(\mathrm{t}_{2 \mathrm{~g}}\right)$ and $\sigma^{*} 3 \mathrm{~d}\left(\mathrm{e}_{\mathrm{g}}\right)$ (RAS2, see Fig. 1) for octahedral coordination or e and $t_{2}$ for tetrahedral, thus allowing for the description of the XAS and RIXS spectra consisting of dipole-allowed $2 p \rightarrow 3 d$ transitions. This active space has been proven to be suitable for calculations of ionic complexes [6,9,11]. In the core-level calculations, all occupied MOs except for the active ones were kept frozen. Spin-orbit coupling (SOC) was treated with the state-interaction (RASSI) method [27] including doublet and quartet states. The computational setup resulted in 155 spin-free states (40 quartet and 115 doublet) and 390 spin-orbit coupled electronic states. Sextet electronic configurations were not considered since they are not possible with the present active space. Their inclusion would require additional active orbitals, e.g. $4 \mathrm{~s}$, which were found to be of minor importance in [9]. Scalar relativistic effects were considered within the Douglas-Kroll-Hess approach [28]. The effect of dynamic correlation was included via second order perturbation theory (RASPT2) [25] with an imaginary level shift of 0.4 hartree to avoid intruder states. In the RASSCF calculations no symmetry has been assumed. RASSCF/RASSI calculations were done with the MOLCAS 8.0 program suite [20]. The assignment of the spectra was done on the basis of occupation number analysis of initial and final states.
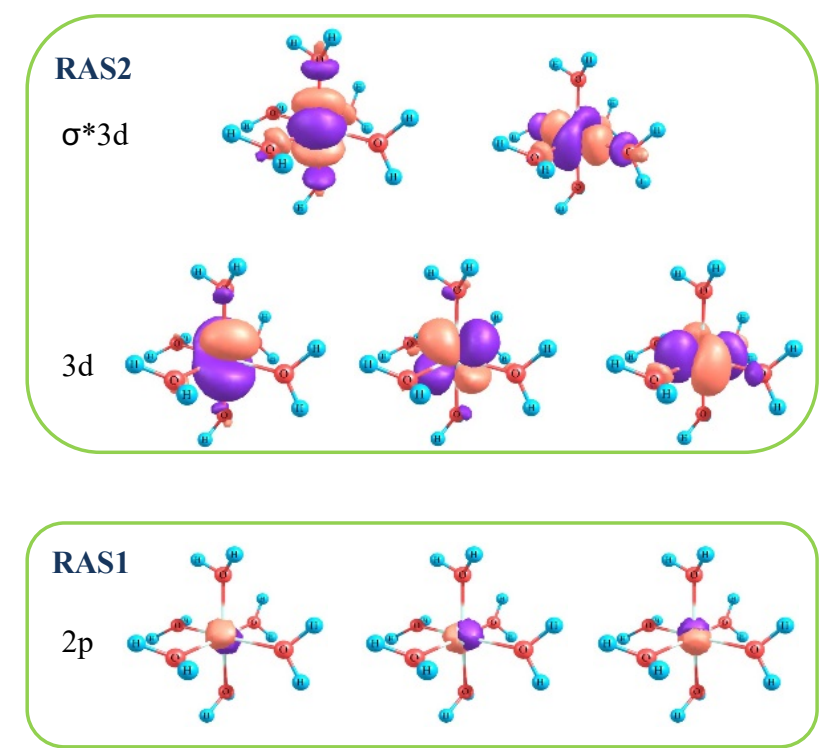

Figure 1: Molecular orbitals included in the active space (RAS1 and RAS2 type) of the RASSCF calculation. The orbitals correspond to the case of $\left[\mathrm{Co}\left(\mathrm{H}_{2} \mathrm{O}\right)_{6}\right]^{2+}$, their variation for the other species is not very pronounced.

The calculations of spectra followed the methodology described in Ref. [2]. The XAS spectrum was calculated according to the Golden Rule expression: 


$$
X(\Omega)=\sum_{g} f\left(E_{g}, T\right) \sum_{i}\left|\left\langle i\left|\mathbf{d} \cdot \mathbf{e}_{1}\right| g\right\rangle\right|^{2} \mathrm{~L}\left(E_{g}+\Omega-E_{i}, \Gamma_{i}\right)
$$

RIXS intensities accounting for electronic coherence effects were obtained according to the Kramers-Heisenberg expression:

$$
R(\Omega, \omega)=\sum_{g} f\left(E_{g}, T\right) \sum_{f} \mathrm{G}\left(E_{g}+\Omega-E_{f}-\omega, \gamma\right)\left|\sum_{i} \sqrt{\frac{\Gamma_{i}}{\pi}} \frac{\left\langle f\left|\mathbf{e}_{2} \cdot \mathbf{d}\right| i\right\rangle\left\langle i\left|\mathbf{d} \cdot \mathbf{e}_{1}\right| g\right\rangle}{E_{g}+\Omega-E_{i}-i \Gamma_{i}}\right|^{2}
$$

Here, $\Omega$ and $\omega$ denote incoming and emitted photon energies; indices $g$, $i$, and $f$ refer to the initial, core excited intermediate, and valence-excited final states; $\mathbf{e}_{1}$ and $\mathbf{e}_{2}$ are polarization vectors of absorbed and emitted photons (chosen to be perpendicular) and $\mathbf{d}$ is the dipole operator. $\mathrm{L}\left(\Omega, \Gamma_{i}\right)$ is a Lorentzian lineshape function with the spectral width $\Gamma_{i}=0.5$ and $0.7 \mathrm{eV}$ for the $\mathrm{L}_{3}$ and $\mathrm{L}_{2}$ edges, respectively; the same $\Gamma_{i}$ are used in Eq. 2. The excitation bandwidth is accounted for by a Gaussian lineshape function $\mathrm{G}(\Omega, \gamma)$ with $\gamma=0.5 \mathrm{eV}$ The initial states were weighted with the Boltzmann factor $f\left(E_{g}, T\right)$ for a temperature $T=300 \mathrm{~K}$.

\section{Results and Discussion}

The studied complexes are listed in Tab. S1 in the Suppl. Mat. They represent the $\left[\mathrm{Co}\left(\mathrm{H}_{2} \mathrm{O}\right)_{6-\mathrm{x}} \mathrm{Cl}_{\mathrm{x}}\right]^{(2-\mathrm{x})+}$ and $\left[\mathrm{Co}\left(\mathrm{H}_{2} \mathrm{O}\right)_{4-\mathrm{x}} \mathrm{Cl}_{\mathrm{x}}\right]^{(2-\mathrm{x})+}$ species being the model for the solution of $\mathrm{CoCl}_{2}$ in water. Experimental data are available for XAS only (transmission mode, $1 \mathrm{M} \mathrm{CoCl}$ solution) [9]. The experimental XAS spectrum reproduced in Figs. 2-3 shows the typical $\mathrm{L}_{3} / \mathrm{L}_{2}$ splitting due to the spin-orbit coupled $2 \mathrm{p}_{3 / 2} / 2 \mathrm{p}_{1 / 2}$ states. The experimental value for the splitting is $15.3 \mathrm{eV}$. While the $\mathrm{L}_{2}$ band shows a weak structure only, for the $\mathrm{L}_{3}$ band one can identify four prominent features, labelled a-d in Fig. 3. They correspond to the experimental energies $776.3 \mathrm{eV}, 777.6 \mathrm{eV}, 778.8 \mathrm{eV}$, and $781.1 \mathrm{eV}$ Before discussing the differences in XAS and RIXS between different complexes, we address some methodological issues.

\subsection{Basis Set Convergence and RASPT2 Correction}

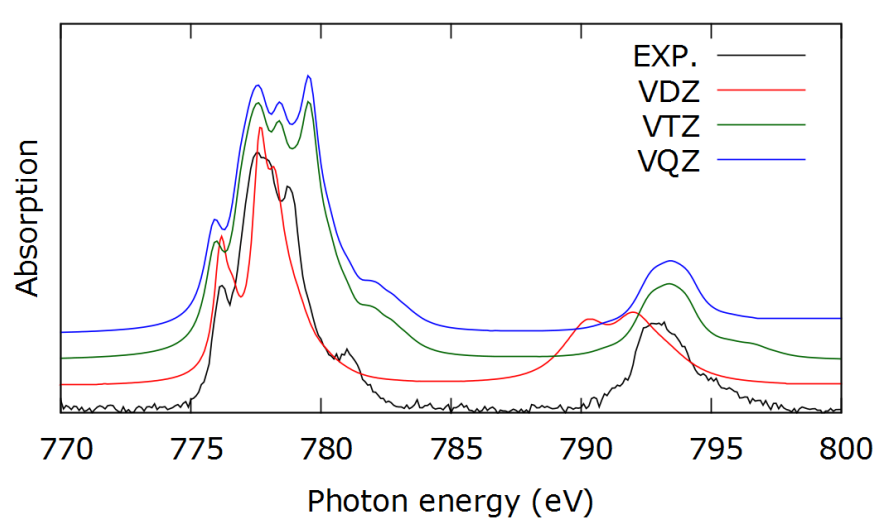

Figure 2: Experimental [9] and calculated RASSCF XAS spectra of $\left[\mathrm{Co}\left(\mathrm{H}_{2} \mathrm{O}\right)_{6}\right]^{2+}$ as obtained for different basis sets. Spectra have been normalized to the highest peak value. The following broadening parameters have been used to adapt to the experimental spectra. VDZ: $0.35 \mathrm{eV}$ from 770 to $777 \mathrm{eV}$, $0.7 \mathrm{eV}$ from 777 to $785 \mathrm{eV}$ and $1.1 \mathrm{eV}$ beyond. VTZ/VQZ: $0.5 \mathrm{eV}$ from 770 to $790 \mathrm{eV}$ and $0.7 \mathrm{eV}$ beyond. 
The dependence of the XAS spectrum on the basis set has been investigated for the complex $\left[\mathrm{Co}\left(\mathrm{H}_{2} \mathrm{O}\right)_{6}\right]^{2+}$ employing the basis sets VDZ, VTZ, and VQZ. Respective results are compared with experiment [9] in Fig. 2. For the VDZ basis set the $\mathrm{L}_{3} / \mathrm{L}_{2}$ splitting is clearly underestimated. Further, in the range of the $\mathrm{L}_{3}$ band it yields only two features. Closer inspection of the optimized active space reveals a high extent of participation of MOs from ligands and a considerable rotation between active space MOs and other occupied orbitals. Hence, the VDZ basis set appears to be not suitable for the calculation of XAS spectra in this case. In contrast, VTZ and VQZ give a very good agreement with experiment and the respective results are essentially identical thus pointing to basis set convergence. Therefore, the VTZ basis set will be used in the following discussions.

Compared with RASSCF the inclusion of the RASPT2 correction for dynamical correlation gives a clear improvement of the agreement with experiment as can be seen in Fig. 3. This holds in particular for the more structured $\mathrm{L}_{3}$ band. Here, most notable is the merging of the double peaks around feature b (RASSCF) into a single peak around $777.6 \mathrm{eV}$ in RASPT2. Further, the intensity ratio between peaks $\mathbf{b}$ and $\mathbf{c}$ is nicely reproduced by RASPT2. For the two minor features one finds for $\mathbf{d}$ and $\mathbf{a}$ an improvement and deterioration, respectively, of their relative position with respect to the main peak $\mathbf{b}$.

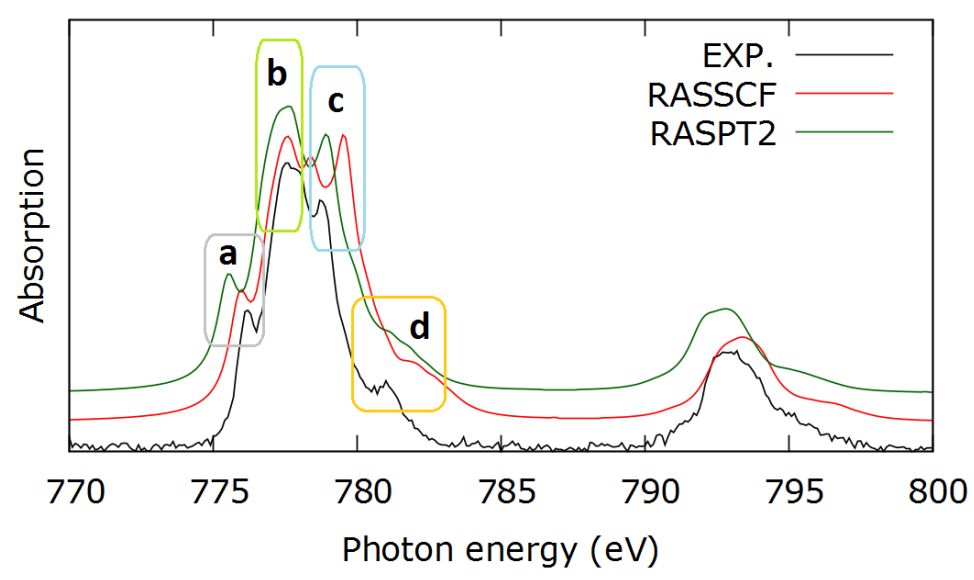

Figure 3: Comparison of RASSCF and RASPT2 XAS spectra for the $\left[\mathrm{Co}\left(\mathrm{H}_{2} \mathrm{O}\right)_{6}\right]^{2+}$ complex. The experimental spectrum for Ref. [9] is also given. The characteristic features of the $L_{3}$ band are marked by labels $\boldsymbol{a}-\boldsymbol{d}$, they correspond to the experimental energies $776.3 \mathrm{eV}, 777.6$ $\mathrm{eV}, 778.8 \mathrm{eV}$, and $781.1 \mathrm{eV}$.

Next we focus on the RIXS spectra as calculated according to Eq. (2) for $\left[\mathrm{Co}\left(\mathrm{H}_{2} \mathrm{O}\right)_{6}\right]^{2+}$. Results are given in Fig. 4 for one-dimensional cuts taken at the excitation energy of the peaks a and $\mathbf{b}$ of the XAS spectrum. Similar to the XAS spectrum, the VDZ basis set gives notably different results as compared with VTZ and VQZ. The latter two show a close agreement, which suggest the VTZ indeed to be a good compromise between accuracy and computational efficiency. 


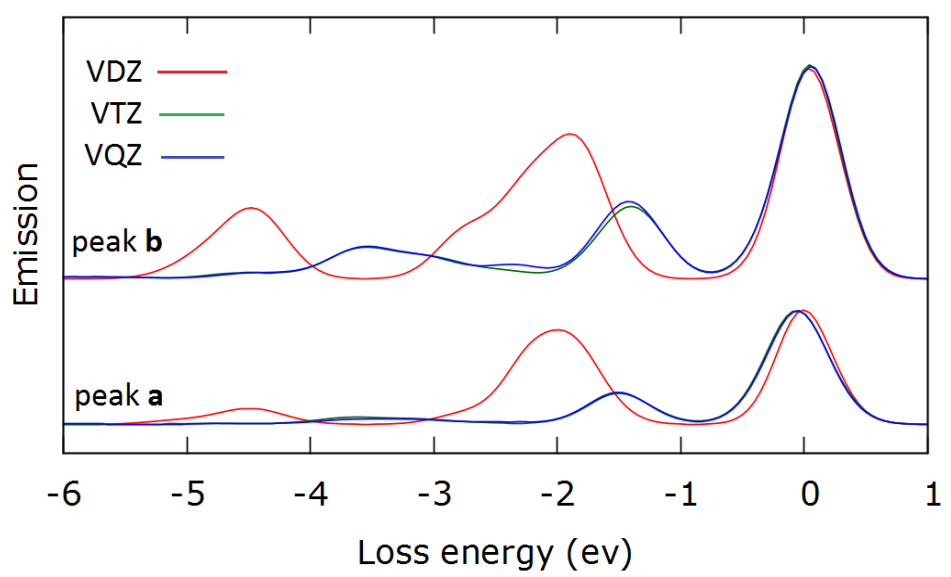

Figure 4: Calculated RASSCF RIXS spectra of $\left[\mathrm{Co}\left(\mathrm{H}_{2} \mathrm{O}\right)_{6}\right]^{2+}$ as obtained for different basis sets as indicated. The results correspond to excitation at the XAS peaks $\boldsymbol{a}$ and $\boldsymbol{b}$ (cf. Fig. 3). Different spectra have been normalized to the elastic peak.

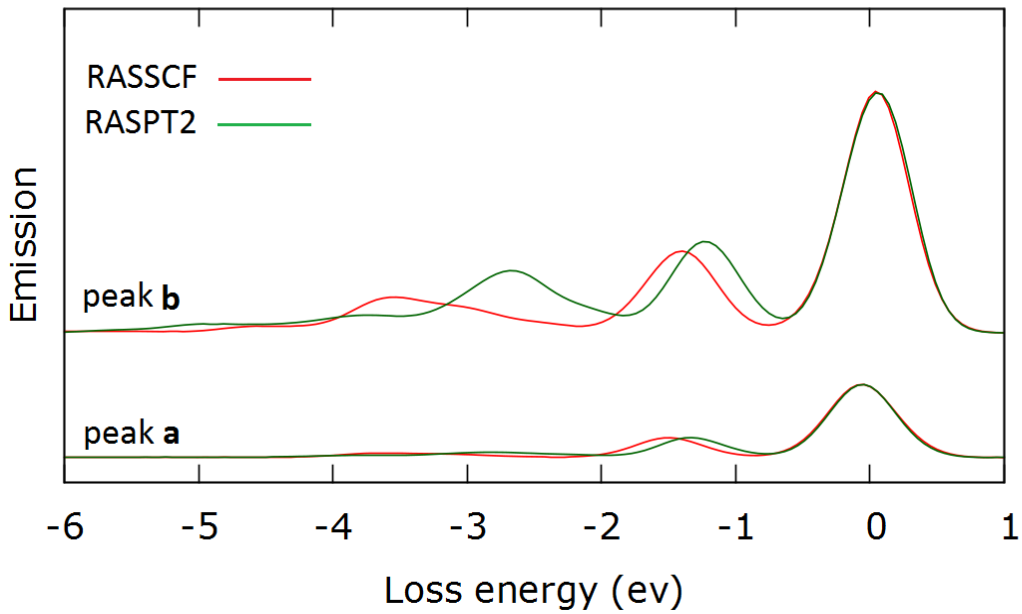

Figure 5: Calculated RIXS spectra of $\left[\mathrm{Co}\left(\mathrm{H}_{2} \mathrm{O}\right)_{6}\right]^{2+}$ as obtained using the RASSCF and RASPT2 methods for the VTZ basis set. The results correspond to excitation at the XAS peak $\boldsymbol{a}$ and $\boldsymbol{b}$ (cf. Fig. 3). Different spectra have been normalized to the elastic peak.

In Fig. 5 we compare the same RIXS cuts obtained for the VTZ basis set and using the RASSCF and RASPT2 methods. Although position and relative intensity of the first inelastic feature between 1 and $2 \mathrm{eV}$ loss energy are reasonably reproduced using RASSCF, this cannot be stated for features at higher loss energies.

Based on this methodological study, we will use the RASPT2 scheme with a VTZ basis set for the following investigations.

\subsection{Effects of Speciation on the XAS Spectrum}

Before we discuss the effects of speciation onto the XAS spectrum we will provide an assignment of the $\mathrm{L}_{3}$ band of $\left[\mathrm{Co}\left(\mathrm{H}_{2} \mathrm{O}\right)_{6}\right]^{2+}$ based on the $3 \mathrm{~d}$ occupation numbers in the RASSCF wave function (for a detailed analysis, see Figs. S1 and S2 in the Suppl. Mat.). Here, one finds that peak a consists of weak but almost purely spin allowed $S \rightarrow S$ transitions (ground state: $S=3 / 2)$ predominantly of $2 \mathrm{p} \rightarrow 3 \mathrm{~d}\left(\mathrm{t}_{2 \mathrm{~g}}\right)$ character. The main peak b but also peaks $\mathbf{c}$ and $\mathbf{d}$ show substantial contributions of spin forbidden $\mathrm{S} \rightarrow \mathrm{S}-1$ transitions (see also Section 3.4). The nature of the transitions contributing to peaks $\mathbf{b}$ to $\mathbf{d}$ is of $2 p \rightarrow 3 d$ ( $e_{g}$ ) 
character mixed with $2 \mathrm{p} \rightarrow 3 \mathrm{~d}\left(\mathrm{t}_{2 \mathrm{~g}}\right)$ as well as contributions from shake-up $3 \mathrm{~d}\left(\mathrm{t}_{2 \mathrm{~g}}\right) \rightarrow 3 \mathrm{~d}\left(\mathrm{e}_{\mathrm{g}}\right)$ transitions. Note that this confirms our previous assignment based on the RASSCF solution [9].

For the tetrahedral complex $\left[\mathrm{Co}\left(\mathrm{H}_{2} \mathrm{O}\right)_{4}\right]^{2+}$, the dominant transition is $2 \mathrm{p} \rightarrow 3 \mathrm{~d}\left(\mathrm{t}_{2}\right)$ with a some contribution from shake-up $3 \mathrm{~d}(\mathrm{e}) \rightarrow 3 \mathrm{~d}\left(\mathrm{t}_{2}\right)$ transitions. This holds throughout the whole $\mathrm{L}_{3}$ band (see Fig. S2 in the Suppl. Mat.). For peaks $\mathbf{b}$ and $\mathbf{c}$, the transitions are a mixture of spin allowed $\mathrm{S} \rightarrow \mathrm{S}$ and spin forbidden $\mathrm{S} \rightarrow \mathrm{S}-1$ contributions. On the other hand, the peaks a and $\mathbf{d}$ consist of pure spin allowed $\mathrm{S} \rightarrow \mathrm{S}$ and pure spin forbidden $\mathrm{S} \rightarrow \mathrm{S}-1$ transitions, respectively.

For the $\left[\mathrm{Co}\left(\mathrm{H}_{2} \mathrm{O}\right)_{6}\right]^{2+}$ complex it is tempting to assign the separation between $\mathbf{a}$ and $\mathbf{b}$ peaks to the d-d or ligand field splitting (in the present case about $1.3 \mathrm{eV}$ ). And in fact the orbital occupation analysis in Fig. S1 would support such a procedure to some extent. However, there are two problems. First, the peak $b$ is rather broad and a reliable assignment would require its decomposition. The issue is even more pressing for the other species where peak a is barely visible as a shoulder. Second, and more importantly, due to the multiconfigurational character of the wave function the correspondence with ligand field theory has to be taken with great caution and results should not be overinterpreted.

XAS spectra for the various species can be found in Fig. 6, their characterization is summarized in Figs. S1 and S2 and Tab. S1 in the Suppl. Mat.. Visual comparison of the spectra clearly leads to the conclusion that the $\left[\mathrm{Co}\left(\mathrm{H}_{2} \mathrm{O}\right)_{6}\right]^{2+}$ species shows the best agreement with experiment. This concerns the width and shape of the $\mathrm{L}_{2}$ band, but even more the peak structure of the $\mathrm{L}_{3}$ band. The following analysis will focus on the $\mathrm{L}_{3}$ band only.

Inspecting the overall $\mathrm{L}_{3}$ lineshape for the different species one can draw the following conclusions. Peak $\mathbf{d}$ is nearly unaffected by the solvation shell, whereas peak a shifts towards higher energies upon $\mathrm{Cl}^{-}$coordination; interestingly the shift is nearly independent on the number of $\mathrm{Cl}^{-}$ions. A notable exception is the tetrahedral $\left[\mathrm{Co}\left(\mathrm{H}_{2} \mathrm{O}\right)_{4}\right]^{2+}$ whose peak a almost coincides with the feature due to the $\mathrm{Cl}^{-}$ligands. Further, only the $\left[\mathrm{Co}\left(\mathrm{H}_{2} \mathrm{O}\right)_{6}\right]^{2+}$ species shows the correct intensity ratio between peaks $\mathbf{b}$ and $\mathbf{c}$. Inspecting the RASPT2 results given in Tab. $\mathrm{S} 1$ (Suppl. Mat.) we can compare the calculated with the experimental $\mathrm{L}_{3} / \mathrm{L}_{2}$ splitting which is $15.3 \mathrm{eV}$. Overall, most species reproduce this value fairly well, with tetrahedral $\left[\mathrm{CoCl}_{2}\left(\mathrm{H}_{2} \mathrm{O}\right)_{2}\right]^{0} /\left[\mathrm{CoCl}\left(\mathrm{H}_{2} \mathrm{O}\right)_{3}\right]^{+}$being closest/farthest $(15.2 \mathrm{eV} / 13.8 \mathrm{eV})$ away from the experimental value; the octahedral $\left[\mathrm{Co}\left(\mathrm{H}_{2} \mathrm{O}\right)_{6}\right]^{2+}$ is with $15.0 \mathrm{eV}$ rather close too. Hence, according to this comparison one can conclude that the octahedral $\left[\mathrm{Co}\left(\mathrm{H}_{2} \mathrm{O}\right)_{6}\right]^{2+}$ is the dominant species in aqueous solution of $\mathrm{CoCl}_{2}$.

Careful analysis of the character of the different transitions given in Figs. S1 and S2 (Suppl. Mat.) one notices that the assignment of the experimental peaks a to $\mathbf{d}$ to calculated transitions of a certain character is all but straightforward. This can be illustrated by comparison of $\left[\mathrm{Co}\left(\mathrm{H}_{2} \mathrm{O}\right)_{6}\right]^{2+}$ and $\left[\mathrm{CoCl}\left(\mathrm{H}_{2} \mathrm{O}\right)_{5}\right]^{+}$. Here, the lowest transition is of $\mathrm{t}_{2 \mathrm{~g}}$ character in both case and the next dominant transition of is $e_{g}$ type. However, the intensity of the $t_{2 g}$ transition in case of the $\left[\mathrm{CoCl}\left(\mathrm{H}_{2} \mathrm{O}\right)_{5}\right]^{+}$species is comparatively weak. In other words, if one would assign the feature to be of $t_{2 g}$ type a careful decomposition of the broad low-energy flank of the $\mathrm{L}_{3}$ band would be required. In terms of ligand field theory one could argue that because of $\mathrm{Cl}^{-}$being a weak ligand, the d-d splitting decreases to an extent that it cannot be easily recognized in the XAS spectrum. Again we emphasize the multiconfigurational nature of the wavefunction which renders this simplified picture to become unreliable as can be seen from the substantial mixing of different characters across the $\mathrm{L}_{3}$ band in Figs. S1 and S2 (Suppl. Mat.). 

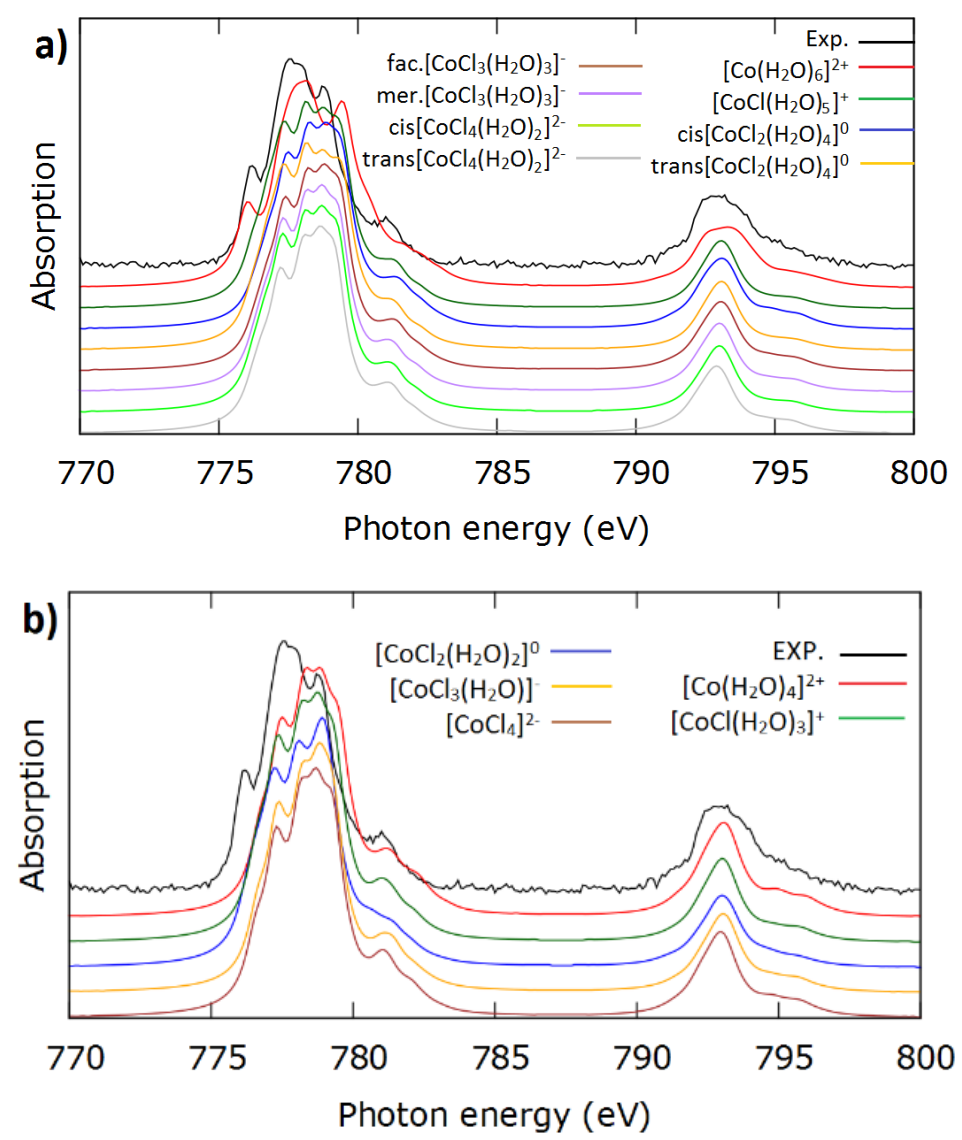

Figure 6: Calculated XAS spectra of all possible six- (panel a) and four-coordinated (panel b) complexes that can be present in aqueous solution. The experimental spectrum from Ref. [9] is also given. The spectra have been aligned at the $L_{2}$ peak position.

\subsection{Effects of Speciation on the RIXS Spectrum}

Being a one-dimensional technique, XAS provides only limited information. The twodimensional RIXS has been shown to be more informative as it connects to highly excited valence state as well. Unfortunately, there are no experimental data available for aqueous $\mathrm{CoCl}_{2}$ at the time being. Therefore, in the following the main goal will be to highlight the differences between the various species.

An overview of the two-dimensional RIXS spectrum for the $\left[\mathrm{Co}\left(\mathrm{H}_{2} \mathrm{O}\right)_{6}\right]^{2+}$ is given in Fig. 7 . The elastic and inelastic features are more pronounced at the $\mathrm{L}_{3}$ edge. Here, one can identify a progression of five inelastic peaks, two of them having notable intensity. In the following we will inspect two one-dimensional cuts, corresponding to excitation energies at the features a and $\mathbf{b}$, which for this compound are of $t_{2 g}$ and $e_{g}$ type, respectively. As mentioned before the character for these features in general varies from specie to specie. 


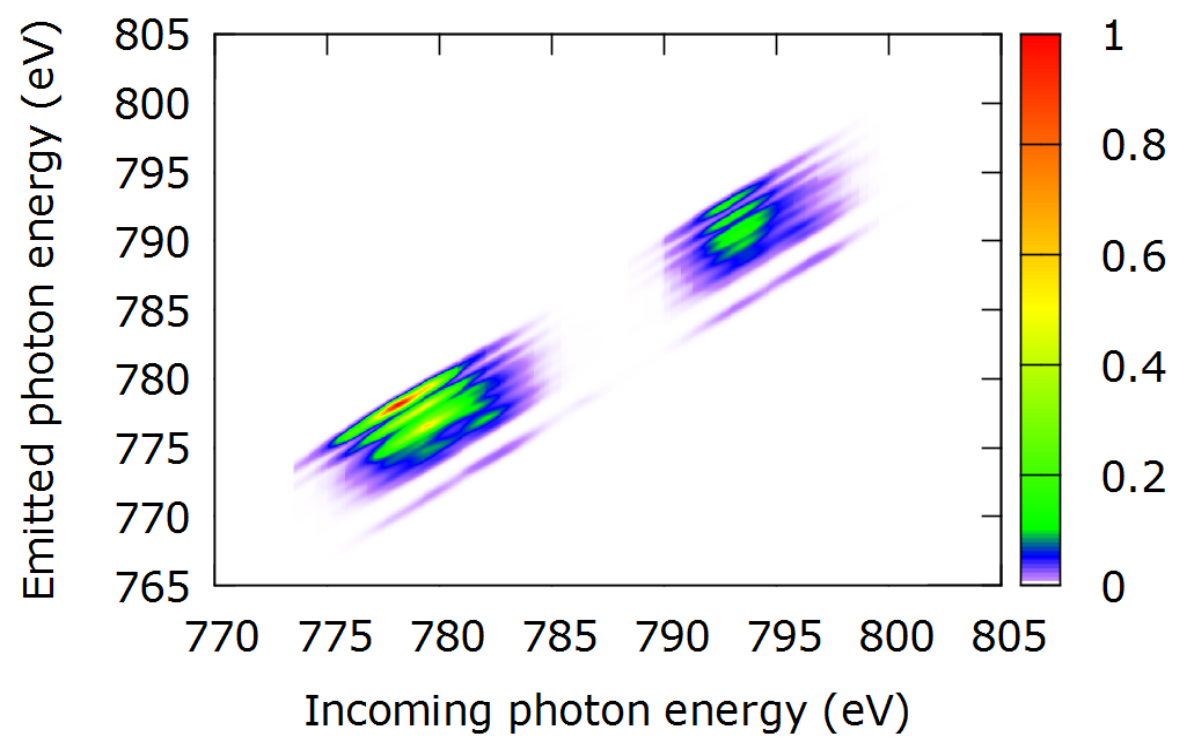

Figure 7: Two-dimensional RIXS spectrum of $\left[\mathrm{Co}\left(\mathrm{H}_{2} \mathrm{O}\right)_{6}\right]^{2+}$ calculated using $\mathrm{RASPT} 2$ with the VTZ basis set.
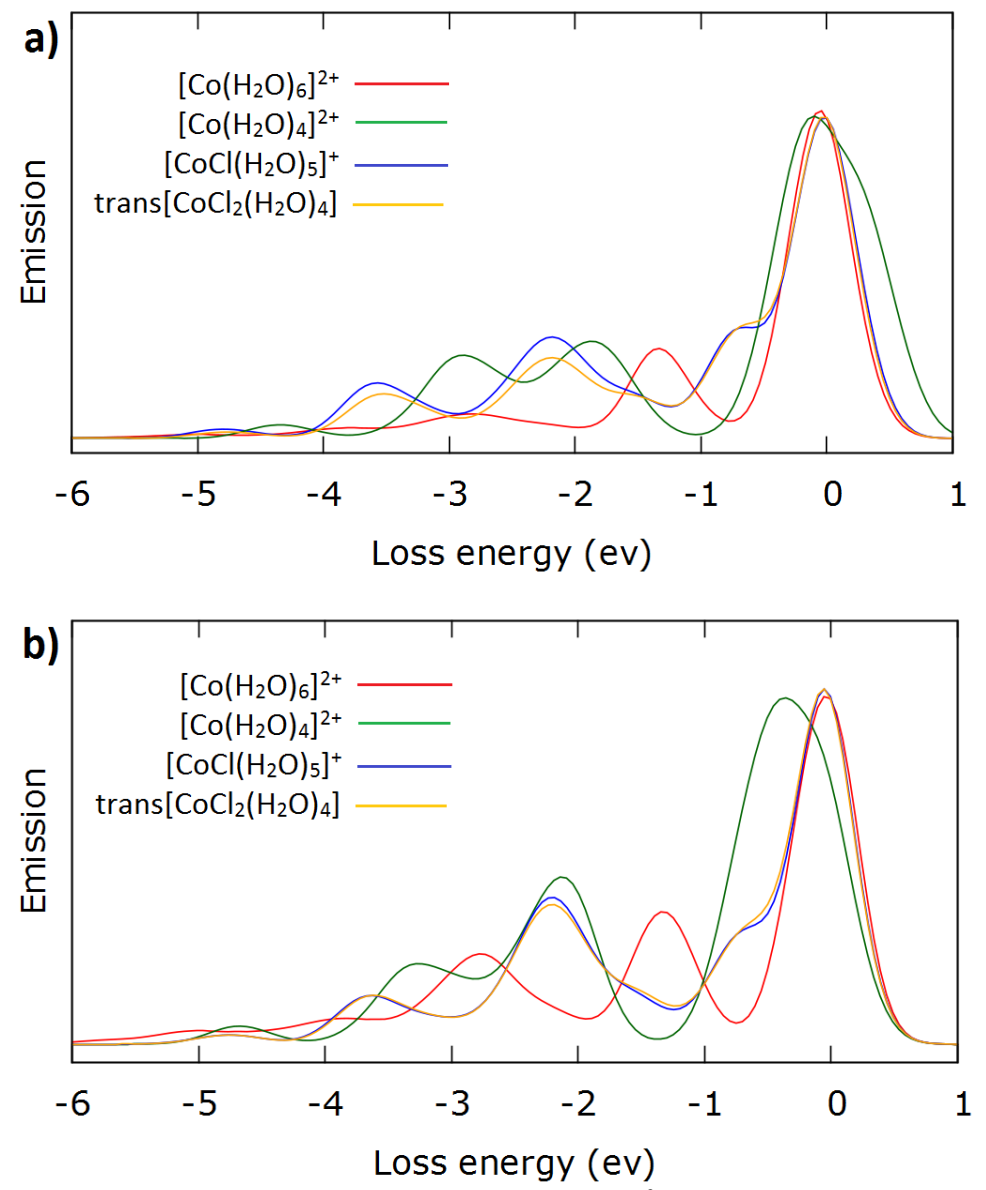

Figure 8: One-dimensional RIXS spectra of different $\mathrm{Co}^{2+}$ complexes: $\left[\mathrm{Co}\left(\mathrm{H}_{2} \mathrm{O}\right)_{6}\right]^{2+},\left[\mathrm{Co}\left(\mathrm{H}_{2} \mathrm{O}\right)_{4}\right]^{2+}$, $\left[\mathrm{CoCl}\left(\mathrm{H}_{2} \mathrm{O}\right)_{5}\right]^{+}$, and trans $\left[\mathrm{CoCl}_{2}\left(\mathrm{H}_{2} \mathrm{O}\right)_{4}\right]^{0}$. Cuts are taken for excitation energies at feature a (panel a) and $\boldsymbol{b}$ (panel b) of the XAS spectrum (compare Fig. 6). The spectra have been normalized to their maxima. 
The calculated RIXS spectra of selected $\mathrm{Co}^{2+}$ complexes are plotted in Fig. 8. These spectra demonstrate more significant differences from each other than in the case of less sensitive XAS. Most notable is the difference between $\left[\mathrm{Co}\left(\mathrm{H}_{2} \mathrm{O}\right)_{6}\right]^{2+}$ and $\left[\mathrm{Co}\left(\mathrm{H}_{2} \mathrm{O}\right)_{4}\right]^{2+}$ RIXS for both excitation energies. In this case, even the form of the elastic peak and adjacent inelastic feature with energy loss of $-1-0 \mathrm{eV}$ does not coincide, evidencing the substantial change in the structure of the low-lying valence electronic levels. The shape of inelastic bands for the presented chlorine-containing complexes is quite similar but deviates substantially from the results for $\left[\mathrm{Co}\left(\mathrm{H}_{2} \mathrm{O}\right)_{6}\right]^{2+}$. This effect is not only due to changes in energies of electronic states because of weaker $\mathrm{Cl}^{-}$ligand, but also due to different SOC mixing (see next Section). Thus, the hexaaqua species can be identified even more distinctly in RIXS spectra than in XAS.

\subsection{Spin-Orbit Coupling}
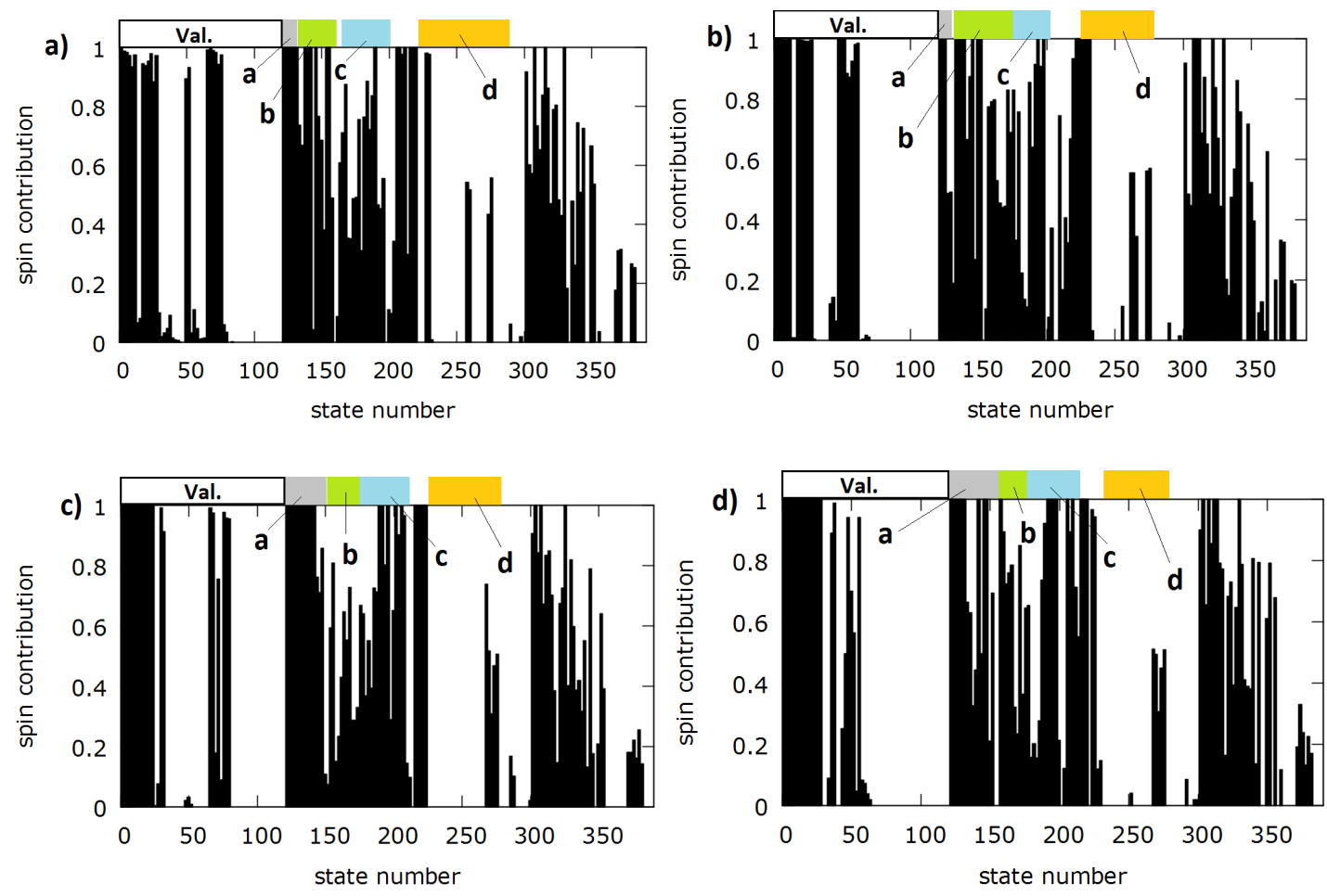

Figure 9: Contributions of states with $\triangle S=0$ (black) and -1 (white) to the spin-orbit coupled wave functions for a) $\left[\mathrm{Co}\left(\mathrm{H}_{2} \mathrm{O}\right)_{6}\right]^{2+}(\mathrm{RASSCF})$, b) $\left[\mathrm{Co}\left(\mathrm{H}_{2} \mathrm{O}\right)_{6}\right]^{2+}(\mathrm{RASPT2})$, c) $\left[\mathrm{CoCl}\left(\mathrm{H}_{2} \mathrm{O}\right)_{5}\right]^{+}(\mathrm{RASSCF})$, and d) $\left[\mathrm{CoCl}\left(\mathrm{H}_{2} \mathrm{O}\right)_{5}\right]^{+}(\mathrm{RASPT2})$.

The SOC is known to play an important role for core-excited states of metal ions $[2,6]$. In addition, it has been shown to be potentially relevant for the highly excited valence states accessed in RIXS spectroscopy [6]. Here, we investigate the effect of SOC on the wavefunction of $\left[\mathrm{Co}\left(\mathrm{H}_{2} \mathrm{O}\right)_{6}\right]^{2+}$ and $\left[\mathrm{CoCl}\left(\mathrm{H}_{2} \mathrm{O}\right)_{5}\right]^{+}$, also putting emphasis on the effect of the RASPT2 correction. The decomposition of the wavefunction for the two species according to $\Delta \mathrm{S}=0$ and -1 contributions within the $L S$ coupling scheme is provided in Fig. 9. The states are numbered and ordered into valence- and core-excited ones; in the latter case we distinguish the regions a-d of the XAS spectrum.

First, we compare the RASSCF (panels a,c) and RASPT2 (panels b,d) results. The mixing of two pure spin states depends not only on the magnitude of the SOC matrix elements, but also 
on their energy mismatch. The PT2 correction causes a modification of these energy gaps. Since the effect can go into both directions, the PT2 correction does not necessarily increase the mixing. In the present case though we notice such an increased spin-mixing for both complexes.

Focusing on the RASPT2 results for $\left[\mathrm{Co}\left(\mathrm{H}_{2} \mathrm{O}\right)_{6}\right]^{2+}$ in Fig. 9b) we notice that the lowest valence states are of $\Delta S=0$ type. The same holds true for the low-energy part of the a feature. Regions $\mathbf{b}$ and $\mathbf{c}$ are of mixed type, while region $\mathbf{d}$ correpsonds dominantly to $\Delta S=-1$ transitions. The situation is similar for the $\mathrm{L}_{2}$ band (beyond state number 300), i.e. starting from $\Delta \mathrm{S}=0$ with increasing energy there is a region of strongly mixed states before $\Delta \mathrm{S}=-1$ transitions dominate at the high energy side of the band. Interestingly, the highly excited valence transitions show only little mixing, i.e. the final RIXS states are either spin-allowed $(\Delta \mathrm{S}=0)$ or spin-forbidden $(\Delta \mathrm{S}=-1)$. Note that the latter could not be observed by direct UV/VIS excitation from the ground state. Changing a ligand to $\mathrm{Cl}^{-}$in $\left[\mathrm{CoCl}\left(\mathrm{H}_{2} \mathrm{O}\right)_{5}\right]^{+}$doesn't show a clear trend for the core-excited states, i.e. only the mixing pattern is redistributed. Only for the region around state number 50 in the valence excited state manifold one notices a certain increase of mixing.

\section{Summary}

In this work, the computational study of the X-ray absorption and resonant inelastic scattering spectra of the solvated $\mathrm{Co}^{2+}$ ions corresponding to the aqueous solution of the $\mathrm{CoCl}_{2}$ is presented. This theoretical study allows disentangling spectroscopic features of different species that might coexist in solution and otherwise cannot be easily distinguished experimentally. The studied complexes include chlorinated species in octahedral, $\left[\mathrm{Co}\left(\mathrm{H}_{2} \mathrm{O}\right)_{6-}\right.$ $\left.{ }_{\mathrm{x}} \mathrm{Cl}_{\mathrm{x}}\right]^{(2-\mathrm{x})+}$, and tetrahedral, $\left[\mathrm{Co}\left(\mathrm{H}_{2} \mathrm{O}\right)_{4-\mathrm{x}} \mathrm{Cl}_{\mathrm{x}}\right]^{(2-\mathrm{x})^{+}}$, coordination. It has been shown that upon proper treatment of electron correlation within the RASPT2 approach, the XAS spectrum of the hexaaqua species $\left[\mathrm{Co}\left(\mathrm{H}_{2} \mathrm{O}\right)_{6}\right]^{2+}$ agrees best with the experiment, whereas other complexes deviate from it. However, configuration mixing and different spin mixing patterns do not allow for an easy assignment of spectra of various species on the transition-to-transition basis. In general, different species demonstrate distinct features in the $\mathrm{L}_{3}$ edge of both XAS and especially RIXS, and this information can be used, e.g., in experimental temperature- and concentration-dependent studies of the solution composition.

\section{Acknowledgment}

Financial support by the Deutsche Forschungsgemeinschaft is gratefully acknowledged (Ku952/10-1 (OK) and BO 4915/1-1 (SIB)). The computational work described in this paper were supported by the King Abdulaziz University High performance computing Center (AZIZ supercomputer, http://hpc.kau.edu.sa)

\section{References}

[1] F. de Groot, A. Kotani, Core Level Spectroscopy of Solids, CRC Press, Boca Raton, 2008.

[2] S.I. Bokarev, O. Kühn, Wiley Interdiscip. Rev. Comput. Mol. Sci. 10 (2019) e1433.

[3] E. Suljoti, R. Garcia-Diez, S.I. Bokarev, K.M. Lange, R. Schoch, B. Dierker, M. Dantz, K. Yamamoto, N. Engel, K. Atak, O. Kühn, M. Bauer, J.-E. Rubensson, E.F. 
Aziz, Angew. Chem. Int. Ed. 52 (2013) 9841.

[4] N. Engel, S.I. Bokarev, E. Suljoti, R. Garcia-Diez, K.M. Lange, K. Atak, R. Golnak, A. Kothe, M. Dantz, O. Kühn, E.F. Aziz, J. Phys. Chem. B 118 (2014) 1555.

[5] P. Wernet, K. Kunnus, I. Josefsson, I. Rajkovic, W. Quevedo, M. Beye, S. Schreck, S. Grübel, M. Scholz, D. Nordlund, W. Zhang, R.W. Hartsock, W.F. Schlotter, J.J. Turner, B. Kennedy, F. Hennies, F.M.F. de Groot, K.J. Gaffney, S. Techert, M. Odelius, A. Föhlisch, Nature 520 (2015) 78.

[6] S.I. Bokarev, M. Khan, M.K. Abdel-Latif, J. Xiao, R. Hilal, S.G. Aziz, E.F. Aziz, O. Kühn, J. Phys. Chem. C 119 (2015) 19192.

[7] C.H.M. van Oversteeg, H.Q. Doan, F.M.F. de Groot, T. Cuk, Chem. Soc. Rev. 46 (2017) 102.

[8] V. Krewald, M. Retegan, N. Cox, J. Messinger, W. Lubitz, S. DeBeer, F. Neese, D.A. Pantazis, Chem. Sci. 6 (2015) 1676.

[9] S.I. Bokarev, M. Dantz, E. Suljoti, O. Kühn, E.F. Aziz, Phys. Rev. Lett. 111 (2013) 83002.

[10] R. Golnak, S.I. Bokarev, R. Seidel, J. Xiao, G. Grell, K. Atak, I. Unger, S. Thürmer, S.G. Aziz, O. Kühn, B. Winter, E.F. Aziz, Sci. Rep. 6 (2016) 24659.

[11] K. Atak, S.I. Bokarev, M. Gotz, R. Golnak, K.M. Lange, N. Engel, M. Dantz, E. Suljoti, O. Kühn, E.F. Aziz, J. Phys. Chem. B 117 (2013) 12613.

[12] I. Josefsson, K. Kunnus, S. Schreck, A. Föhlisch, F. de Groot, P. Wernet, M. Odelius, J. Phys. Chem. Lett. 3 (2012) 3565.

[13] P. Wernet, K. Kunnus, S. Schreck, W. Quevedo, R. Kurian, S. Techert, F.M.F. de Groot, M. Odelius, A. Föhlisch, J. Phys. Chem. Lett. 3 (2012) 3448.

[14] W. Liu, S.J. Borg, D. Testemale, B. Etschmann, J.-L. Hazemann, J. Brugger, Geochim. Cosmochim. Acta 75 (2011) 1227.

[15] C. Bresson, C. Darolles, A. Carmona, C. Gautier, N. Sage, S. Roudeau, R. Ortega, E. Ansoborlo, V. Malard, Metallomics 5 (2013) 133.

[16] N.A. Besley, F.A. Asmuruf, Phys. Chem. Chem. Phys. 12 (2010) 12024.

[17] B.O. Roos, R. Lindh, P.Å. Malmqvist, V. Veryazov, P.-O. Widmark, Multiconfigurational Quantum Chemistry, Wiley, Hoboken, New Jersey, 2016.

[18] R. V Pinjari, M.G. Delcey, M. Guo, M. Odelius, M. Lundberg, J. Comput. Chem. 37 (2016) 477.

[19] M. Preuße, S.I. Bokarev, S.G. Aziz, O. Kühn, Struct. Dyn. 3 (2016) 62601.

[20] G. Grell, S.I. Bokarev, B. Winter, R. Seidel, E.F. Aziz, S.G. Aziz, O. Kühn, J. Chem. Phys. 143 (2015) 74104.

[21] A. Moguilevski, M. Wilke, G. Grell, S.I. Bokarev, S.G. Aziz, N. Engel, A.A. Raheem, O. Kühn, I.Y. Kiyan, E.F. Aziz, ChemPhysChem 18 (2017) 465.

[22] J. Norell, G. Grell, O. Kühn, M. Odelius, S.I. Bokarev, Phys. Chem. Chem. Phys. 20 (2018) 19916.

[23] G. Grell, O. Kühn, S.I. Bokarev, Phys. Rev. A 100 (2019) 42512.

[24] M.J. Frisch, G.W. Trucks, H.B. Schlegel, G.E. Scuseria, M.A. Robb, J.R. Cheeseman, G. Scalmani, V. Barone, B. Mennucci, G.A. Petersson, H. Nakatsuji, M. Caricato, X.

Li, H.P. Hratchian, A.F. Izmaylov, J. Bloino, G. Zheng, J.L. Sonnenberg, M. Hada, M. Ehara, K. Toyota, R. Fukuda, J. Hasegawa, M. Ishida, T. Nakajima, Y. Honda, O. Kitao, H. Nakai, T. Vreven, J.J.A. Montgomery, J.E. Peralta, F. Ogliaro, M. Bearpark, J.J. Heyd, E. Brothers, K.N. Kudin, V.N. Staroverov, R. Kobayashi, J. Normand, K. Raghavachari, A. Rendell, J.C. Burant, S.S. Iyengar, J. Tomasi, M. Cossi, N. Rega, J.M. Millam, M. Klene, J.E. Knox, J.B. Cross, V. Bakken, C. Adamo, J. Jaramillo, R. Gomperts, R.E. Stratmann, O. Yazyev, A.J. Austin, R. Cammi, C. Pomelli, J.W. Ochterski, R.L. Martin, K. Morokuma, V.G. Zakrzewski, G.A. Voth, P. Salvador, J.J. 
Dannenberg, S. Dapprich, A.D. Daniels, O. Farkas, J.B. Foresman, J. V Ortiz, J. Cioslowski, D.J. Fox, Gaussian 09, Revision D.01, Gaussian Inc., Wallingfort, CT, 2009.

[25] P.-Å. Malmqvist, A. Rendell, B.O. Roos, J. Phys. Chem. 94 (1990) 5477.

[26] P.-O. Widmark, P.Å. Malmqvist, B.O. Roos, Theor. Chim. Acta 77 (1990) 291.

[27] P.Å. Malmqvist, B.O. Roos, B. Schimmelpfennig, Chem. Phys. Lett. 357 (2002) 230.

[28] M. Douglas, N.M. Kroll, Ann. Phys. (N. Y). 82 (1974) 89. 